London School of Hygiene and Tropical Medicine, London, UK

Cite this as: BMJ 2021;375:n3055 http://dx.doi.org/10.1136/bmj.n3055 Published: 09 December 2021

\section{Public health and politics are inseparable, as Omicron and the UK's response remind us}

\author{
Martin McKee professor of European public health
}

It was always a matter of when rather than if. The emergence of a new variant of SARS-CoV-2 with the ability to escape prior immunity was inevitable, given the evolutionary pressures on the virus and its ability to mutate. ${ }^{1}$ And we can already say with certainty that Omicron will not be the last variant. Indeed, there are already reports of a further mutation that undermines the ability to track Omicron by means of its signature on PCR testing-the S Gene Target Failure. $^{2}$

Although the evidence is still fragmentary, we have learnt a great deal about this variant in only a few weeks, not least because of the remarkable work done by some amazing South African scientists. Genome sequencing has found at least four sets of mutations causing concern-with potential to attach more strongly to cells, to reproduce more quickly, and to evade both innate and antibody-induced immunity. ${ }^{3}$ Virologists and immunologists have shown that the ability of antibodies from vaccination or prior infection are much less effective in neutralising it, although the precise estimates differ. ${ }^{4}$

Epidemiologists in South Africa and elsewhere have shown that infections are spreading far faster than previously, with accounts of superspreading events suggesting an exceptionally high attack rate. And although some initial reports suggested that it may only cause mild infections, the analysts at South Africa's National Institute for Communicable Diseases have established an excellent surveillance system that is showing a steep increase in hospitalisations. ${ }^{5}$ Putting all of this together, those advising the British government are right to be concerned. And they have now convinced ministers to act on their warnings. The Westminster government's Plan B has finally been activated for England (many of its provisions are already in place in the devolved nations). ${ }^{6}$

So, what will change? In a reversal of previous efforts to encourage more people to go into offices, they will be advised to work from home, if possible, from 13 December. Facemasks will be compulsory in more settings, such as theatres and cinemas, from 10 December. NHS covid passes will be required in venues with large numbers of people. And those in contact with someone who has covid will be required to take a lateral flow test daily.

When assessing pandemic countermeasures, it is always a good idea to go back to first principles. Decisions should be based on what we know about how this virus spreads. We now know that the predominant mode of spread is airborne, with transmission most likely in any setting where large numbers of people are mixing for prolonged periods, in enclosed poorly ventilated spaces, without face coverings. From this it follows that anything we do should seek to minimise these opportunities. Obviously, some of the measures proposed do this but there are many glaring gaps and inconsistencies. How can it be sensible to have an exemption to the requirement to wear masks for those who are singing, especially given the many superspreading events associated with this activity ${ }^{7}$ As comedians have noted, we are now in a situation where meeting at work is discouraged, but meeting at a party is not. ${ }^{8}$ Even though one of the key lessons from earlier waves was the importance of offering support to those who need to isolate, the new measures include no provisions for doing so. ${ }^{9}$ What is being done to support NHS and social care staff, who must be dreading the prospect of another rapid increase in cases? What about schools, where covid-19 has been spreading for months? If suggestions from South Africa that children are being especially affected by Omicron prove accurate, surely they should be a priority? And are the measures too late? The new variant has already spread widely across the UK, with widespread acceptance that the figures we have are a substantial underestimate. So, while there are some things to be welcomed in Plan B, it is very far from a scientifically coherent package and, given what we already know, it seems very unlikely to be able to control the spread of Omicron.

Yet many of these questions have been overshadowed by something else, the events in Downing Street last December. Precisely what happened then remains far from clear, not least because explanations from ministers stretch credibility. Boris Johnson, the prime minister, and other ministers have repeatedly refused to say whether a party took place at a time when it would have been unlawful given the covid restrictions then in place, instead insisting that the guidance was followed. ${ }^{10}$ Much may depend on the definition of the word "party," which now, to the surprise of many, seems to exclude an event attended by 40 or more people in which wine and cheese were consumed and games were played. An emerging issue seems to be whether it was planned in advance, raising questions about whether the term "surprise party" is actually an oxymoron. ${ }^{11}$ All should become clear sometime in 2022 when Simon Case, cabinet secretary, has completed his investigation, although having done so he may then wish to consider why, seemingly, there is no easily obtainable record of who comes and goes in Downing Street.

In fairness the prime minister has now apologised, although not for whatever may have taken place on the 18 December 2020 (or for any of the other similar events that are reported to have taken place in Downing Street around the same time when London was in lockdown). Rather, he was sorry for the impression given by a film clip of his spokesperson 
Allegra Stratton, who was laughing at a preparation session for a press briefing when asked about "this fictional party."

This matters. Behavioural scientists have long pointed to the importance of trust in messengers and clarity of messaging. At the end of the first wave of the pandemic, when the message "Stay Home” was replaced by "Stay Alert," many people, quite reasonably, were puzzled by what this meant given the threat came from a virus that was invisible to them. Not unreasonably, the public has struggled with continually changing, and often poorly explains policies creating what has been described as "Alert Fatigue."12 Bizarrely, in response to a question the day following the announcement of the most recent measures, the prime minister's spokesperson is reported to have suggested that someone who decided to sing in a supermarket would be exempt from mask wearing if they had a "reasonable excuse."13

Inevitably, those, including many Conservative MPs, who are ideologically opposed to many of the measures needed to control covid transmission are exploiting this confusion. This is not helped by the approach taken by the Metropolitan Police, who have, to widespread incredulity, said that they do not investigate events that took place in the past and who, despite having many police officers guarding Downing Street at all times, seem unable to find any evidence of what took place there. ${ }^{14}$ Those charged with breaching the covid regulations and whose cases are still going through the courts may have sympathy with the narrative that it is "one rule for them and another for us." Given that the prime minister can rely on support from other parties, opposition from his own side should not prevent passage of the necessary legislation, although it could create political problems within the Conservative Party.

But will this make any difference to people's behaviour? We have some directly relevant evidence from research on what has become known as the "Cummings effect" after the prime minister's advisor who travelled away from London after contracting covid. ${ }^{15}$ That was associated with a marked decline in trust in the government and a more rapid decline in adherence to guidelines among those in England, but not in Scotland or Wales. It is also likely to encourage the minority of people who reject any measures they feel are imposed on them by the government. But throughout the pandemic the vast majority of the population have adhered to guidance, often taking a much more cautious line than the government. ${ }^{16}$ This, at least, is reassuring. Of course, it would help if the messaging by the government was clearer. But in all of this, the prime minister must balance science and politics, a particularly difficult feat when even his strongest supporters are asking whether he has become a liability for his party. The result of the forthcoming by-election in Shropshire, ironically precipitated by issues related to contracts for covid tests, may provide the answer.

\section{Competing interests: MMK is a member of Independent SAGE}

Provenance and peer review: Commissioned, not peer reviewed

1 Priesemann V, Balling R, Bauer S, etal. Towards a European strategy to address the COVID-19 pandemic. Lancet 2021;398:838-9. doi: 10.1016/S0140-6736(21)01808-0. pmid: 34384539

2 The Guardian. Scientists find 'stealth' version of Omicron that may be harder to track https://www.theguardian.com/world/2021/dec/07/scientists-find-stealth-version-of-omicronnot-identifiable-with-pcr-test-covid-variant

3 Q\&A. Imperial experts discuss new variant Omicron https://www.imperial.ac.uk/news/232217/qaimperial-experts-discuss-variant-omicron/

4 Scientists recommend COVID booster shots after 4 studies show vaccines may be less effective against the Omicron variant https://fortune.com/2021/12/08/scientists-recommend-covidbooster-shots-studies-2-shot-vaccines-less-effective-against-omicron-variant/

5 National Institute for Communicable Diseases. https://www.nicd.ac.za/diseases-a-z-index/diseaseindex-covid-19/surveillance-reports/daily-hospital-surveillance-datcov-report/
6 Torjesen I. Covid restrictions tighten as omicron cases double every two to three days. BMJ 2021;375. doi: 10.1136/bmj.n3051.

7 Superspreading drives the COVID pandemic - and could help to tame it. Nature. https://www.nature.com/articles/d41586-021-00460-x

8 Twitter Michael Spicer. https://twitter.com/MrMichaelSpicer/status/1468691282193227782?s=2

9 Tackling Covid-19: A case for better financial support to self-isolate Nuffield Trust https://www.nuffieldtrust.org.uk/research/tackling-covid-19-a-case-for-better-financial-supportto-self-isolate

10 No 10 party: more Downing Street gatherings now under the spotlight. The Guardian. https://www.theguardian.com/uk-news/2021/dec/08/no-10-party-more-downing-street-gatherings-now-under-the-spotlight

11 One big question for Cabinet Secretary: Does a party have to be premeditated to break the rules? https://www.itv.com/news/2021-12-09/the-big-question-does-a-party-have-to-be-premeditatedto-break-the-rules

12 The public aren't complacent, they're confused-how the UK government created "alert fatigue." BMJ Opinion. February 2021. https://blogs.bmj.com/bmj/2021/02/19/the-public-arent-complacentthey-are-confused-how-the-uk-government-has-created-alert-fatigue/

13 Twitter. Tom Newton Dunn. https://twitter.com/tnewtondunn/status/1468926687287070735?s=20

14 Downing Street party. Police will not investigate due to 'lack of evidence' BBC News. https://www.bbc.co.uk/news/uk-politics-59588413

15 Fancourt D, Steptoe A, Wright L. The Cummings effect: politics, trust, and behaviours during the COVID-19 pandemic. Lancet 2020;396:464-5 doi: 10.1016/S0140-6736(20)31690-1. pmid: 32771083

16 For psychologists, the pandemic has shown people's capacity for cooperation. The Guardian. https://www.theguardian.com/commentisfree/2021/jan/02/psychologists-pandemic-cooperationgovernment-public-britain 